\title{
Motor neurodevelopment of preterm children cohort until one year of corrected age according to alberta infant motor scale
}

\begin{abstract}
Introduction: The Alberta Infant Motor Scale (Alberta Scale in the text) is used globally to evaluate the motor development, in both preterm and term children under the 18 months of birth, in Colombia the tool is used, but there is few information about the results it gives when applied in our environment.
\end{abstract}

Objectives: characterize a retrospective cohort of children under 1 year according to the Alberta Scale to generate information about the results of the application of this one in Colombian population attended in a fourth level hospital.

Methods: Descriptive, retrospective, cross-sectional study, where the medical histories of 411 children with corrected age between 0 and 12 months of birth and background of gestational age under 40 weeks were evaluated. To all the children were applied the Alberta Scale between 2010 and 2016 and the scores according to this were statistically analyzed in a descriptive form.

Results: Most of the patients were classified by the scale as "normal development" as it was expected from their background, the children of our sample present lower scores than the original Canadian sample at all the ages.

Conclusion: The scale showed to be useful at the screening of the normal child, however, the patients presented lower scores when evaluated by the scale than in the original study, evidence is generated about the need to validate the scale in Colombia and to generate reference curves for this.

Keywords: premature newborn, infant development, motor activity
Volume 3 Issue I - 2018

\author{
Doris Valencia Valencia,' Edwin Alberto Vega \\ Vargas, ${ }^{2}$ Rodrigo Benavides Núñez, ${ }^{3}$ David \\ Montoya Ossa ${ }^{4}$ \\ 'Médico Epidemióloga, Medicina Física y Rehabilitación \\ Universidad Nacional de Colombia, Colombia \\ ${ }^{2}$ Medico Universidad Surcolombiana, Colombia \\ ${ }^{3}$ Estudiante de XII semestre de la carrera de Medicina de la \\ Universidad Nacional de Colombia, Colombia \\ ${ }^{4}$ Estudiante de V semestre de la carrera de Medicina de la \\ Universidad Nacional de Colombia, Colombia
}

\author{
Correspondence: Doris Valencia Valencia, Médico \\ Epidemióloga .Medicina Física y Rehabilitación Universidad \\ Nacional de Colombia, Profesora Asociada Universidad \\ Nacional de Colombia, Colombia, Tel 3176475518, \\ Email dvalenciava@unal.edu.co
}

Received: December 28, 2017 | Published: February 0I, 2018

\section{Introduction}

The motor development of children with background of prematurity (gestational age under 37 weeks) presents significant differences in relation to the term children, in both long and short term, because they are more likely to present affections and pathologies directly related to this like cerebral palsy or some with indirect relation that impact the patient's overall development such as visual, auditory or cognitive alterations, resulting from the bad adaptation to the extrauterine environment. ${ }^{1-3}$

The Alberta Infant Motor Scale is a tool that started to developed in 1989 in the locality of Alberta Canada given the few standardization in the evaluation of the early infant motor development that existed at that moment, the authors chose 84 items that valued the early gross motor development based on the descriptive literature that they had at the moment, and divided them in four sets according to the position in which the child was going to be evaluated, 58 items were chosen to later develop the validation and reliability analysis of the scale with the help of the Pediatric Division of the Canadian Association of Physiotherapists and a panel of international experts in motor development, in several stages. ${ }^{4}$

The description of the construction and validation of the Alberta Scale was published in 1992 and the definition of punctuation norms and evaluation percentiles was published in 1994 in book form with the name of "Motor Assessment of the Developing Infant", as a product of the longitudinal study with the scale of 2202 children born in that locality between 1990 and $1992 .{ }^{5}$ The scale evaluates the gross motor skills of children between 0 and 18 months of birth and has been widely used for this purpose in a great variety of countries, being revalidated for this purpose 20 years later with a chosen sample of six hospitals from different cities of Canada, and with criteria to demographically and ethnically represent the Canadian population ${ }^{6}$ the scale has also being validated in diverse countries such as Greece, Japan and Brazil, the last one being specially important because of the potential similarities between its population and ours. ${ }^{7-9}$ Given its wide diffusion local reference curves and transcultural analyses have been realized, to adapt it to the different conditions of the local population, including again Brazil among the countries that have this type of studies showing the versatility of the tool and also the requirement of creation of reference values for specific environments. ${ }^{10-12}$ without the existence of similar studies in our country, in Colombia the interobserver reproducibility has been prove. ${ }^{13}$

The scale evaluates the gross motor abilities of the children in 4 positions that are part of their ontogenic development: prone, supine, seated and standing, depending on which activities they can develop, they are assigned with a total score and are placed in motor performance percentiles according to their age, each patient gets a point for each completed activity. The scale was developed as a screening tool of the normal neurodevelopment, and the evaluation among this comes from de fact that if the child is placed in the $0-10$ percentile implies abnormal development, 11-25 suspicion of normal development, and from 26 onwards it is normal. ${ }^{5}$ 
The international literature reports that patients with prematurity background show different scores in comparison to the full-term children when evaluated with the Alberta Scale and the Brazilian reference curves show lower scores for almost all ages in term children compared to the original sample from Canada. ${ }^{10,14}$ For the correct evaluation of the premature child, the age is corrected as if he would born on the day he completed 40 weeks, which is necessary until 2 completed years of corrected age, an action that is accordance with the guidelines of the classification of premature babies according to the gestational age of the American College of Obstetriatians and Gynaecologists (ACOG) which defines a term newborn who presents a corrected age between 39 weeks $0 / 7$ days and 40 weeks $6 / 7$ of gestation, creating the early term and others in relation to the gestational age of the newborn. ${ }^{15,16}$

Given that the Alberta Scale is widely used in the context of the evaluation of motor development worldwide, which has been revalidated for its current use, which has been validated in other countries and especially that it is currently used in our country, with too little information about its application in Colombia, it is necessary to generate descriptive information about the results of our patients evaluation with this scale in our environment, for the case of this study with patients with prematurity background, and so give previous evidence to more complex studies that could validate the scale, generate country reference curves or formulate its usefulness in our country.

\section{Methods}

Descriptive, retrospective, cross-sectional study that evaluates the clinical histories of 411 children with corrected age between 0 and 12 months of birth and background of gestational age under 40 weeks, born in Bogota, To whom the Alberta Scale was applied during the follow-up consultation of premature child in a fourth level hospital, between the years 2010 to 2016 . The information was obtained during the consult of the initial assessment or follow up, in which a format was filled with general information about prenatal, perinatal and postnatal aspect of the child. The patients attended in the company of their keepers for the assessment by the specialty of physical medicine and child rehabilitation through several tools that included the Alberta Scale, which is going to be studied here.

The tool was applied to each patient, a point was added for each activity that the child managed to achieve in the different positions, the total score was added in a physical format designed for that purpose, which detailed the items for each range of age in the prone, supine, sitting and standing positions and then it came the placement of the patients by percentile according to the graph that correlates them with the score of each child, graph obtained from the study that generated the evaluation norms with the scale. ${ }^{5}$ Each patient was evaluated in the consult, being awake and calm in such a way that the different activities that the tool requires were performed as spontaneously as possible, in general those are gross motor activities that require a certain level of concentration of the evaluated child, according to the age, and sometimes of the active stimulus of the activity by the evaluators, that happens with some items by requirement of the tool itself or the situation; the evaluation was carried out in a calm environment and in the permanent company of the keepers.

The 411 histories evaluated had the Alberta Scale format fully full filled. The data were tabulated in Excel and then analyzed statistically in the SPSS 24 software with descriptive statistics, due to the nature of the study and the sample.

\section{Results}

Of the 411 histories evaluated, $48 \%$ were male patients $52 \%$ female patients. The most frequent risk factors associated with prematurity were jaundice and intrauterine growth restriction (Table 1) patients from 0 to 12 months of age were evaluated, the average chronological age was 4.79 months, the average corrected age was 3.42 months, the percentage of average development by Alberta was $40.3 \%, 52.9 \%$ of the patients were at the normal development level, $27.3 \%$ of the patients in the level of suspicious abnormal development, and 19.7\% in the abnormal development level. We also compared the means of the scores by age of the patients of our sample with the means of the Canadian sample, we found that the mean of the score is lower for all ages in our sample, even at the highest ages where our sample has few patients and the comparison may be less significant (Table 2).

Table I The most frequent risk factors associated with prematurity were jaundice and intrauterine growth restriction

\begin{tabular}{|c|c|c|}
\hline Variable & Frequency & Percentage \\
\hline \multicolumn{3}{|l|}{ Gestational age(weeks) } \\
\hline$<26$ & 3 & 0.7 \\
\hline $26-32$ & 61 & 14.8 \\
\hline $33-36$ & 225 & 54.7 \\
\hline $37-40$ & 122 & 29.7 \\
\hline \multicolumn{3}{|l|}{ Maternal age(years) } \\
\hline$<16$ & 14 & 3.4 \\
\hline 17-34 & 353 & 85.9 \\
\hline$>34$ & 44 & 10.7 \\
\hline Vaginal delivery & 188 & 45.7 \\
\hline Instrument & 17 & 4.1 \\
\hline Cesarean section & 223 & 54.3 \\
\hline Jaundice & 270 & 65.7 \\
\hline Revival & 35 & 8.5 \\
\hline Intrauterine growth restriction & 60 & 14.6 \\
\hline Cardiac pathology & 7 & 1.7 \\
\hline Sepsis & 37 & 9 \\
\hline Intracranial hemorrhage & 16 & 3.9 \\
\hline Enterocolitis & 8 & 1.9 \\
\hline Hypoglycemia & 41 & 9.9 \\
\hline Fetal suffering & 46 & 11.2 \\
\hline
\end{tabular}

We then proceeded to classify the patients according to the percentile in which they were placed considering that by definition a percentile is a statistical measurement of placement of one data set that, when being ordered the set, it indicates the value of a given percentage of observations, in this case of children according to the motor performance measured by the Alberta Scale, the percentage of children of our sample at each percentile of the original sample should be similar to the percentile itself if our sample had a motor development distribution similar to the original sample according to the scale. 
Table 2 Compared the means of the scores by age of the patients of our sample with the means of the Canadian sample

\begin{tabular}{|c|c|c|c|}
\hline Age & Number of patients & Mean & Standard deviation \\
\hline \multirow[t]{2}{*}{$0-1$ months } & 129 & Our sample (N)4.37 & NI.59 \\
\hline & & Canada (C)4.55 & $\mathrm{Cl} .35$ \\
\hline \multirow[t]{2}{*}{ I-2 months } & 73 & N6.9 C7.30 & $\mathrm{N} 2.22$ \\
\hline & & & $\mathrm{Cl} .95$ \\
\hline \multirow[t]{2}{*}{$2-3$ months } & 50 & N9.02 & $\mathrm{N} 2.53$ \\
\hline & & C9.8 & C 2.45 \\
\hline \multirow[t]{2}{*}{ 3-4 months } & 26 & NI0.57 & N 2.46 \\
\hline & & $\mathrm{Cl} 2.6$ & C 3.3 \\
\hline \multirow[t]{2}{*}{ 4-5 months } & 23 & NI4.69 & N3.75 \\
\hline & & $\mathrm{Cl} 7.8$ & C4.I \\
\hline \multirow[t]{2}{*}{$5-6$ months } & 34 & NI9.73 & N3.98 \\
\hline & & $\mathrm{C} 23.2$ & C4.75 \\
\hline \multirow[t]{2}{*}{ 6-7 months } & 33 & N24.3 & N7.18 \\
\hline & & C28.3 & C5.5 \\
\hline \multirow[t]{2}{*}{ 7-8 months } & 10 & N30.00 & N8.77 \\
\hline & & C 32.2 & C6.85 \\
\hline \multirow[t]{2}{*}{ 8-9 months } & 7 & N36.28 & N6.04 \\
\hline & & C39.7 & C8.7 \\
\hline \multirow[t]{2}{*}{$9-10$ months } & 8 & N42.37 & N8.87 \\
\hline & & C45.4 & C7.45 \\
\hline 10-II months & 10 & $\mathrm{~N} 43.3 \mathrm{C} 49.3$ & N8.30 C5.9 \\
\hline 11-12 months & 8 & N5I C5I.25 & N6. 16 C7.I \\
\hline
\end{tabular}

What we found is that, except for ages 11-12 months, at least $90 \%$ and in 5 of the 12 age ranges at least the $20 \%$ of the patients were of the patients were found to be below the $75^{\text {th }}$ percentile in all the others ages and at least $62.5 \%$ were placed below the $50^{\text {th }}$ percentile in all ages reaching even the $100 \%$ between the $3-4$ months and between the 8-9 months, also highlighting that in 8 of the 12 ages ranges at least $40 \%$ of the patients were found to be below the $25^{\text {th }}$ percentile found to be below the $10^{\text {th }}$ percentile and clarifying that our biggest subsample, the patients aged $0-1$ months, the distribution is more similar to the Canadian sample, but even so more than $90 \%$ of the patients are below the $75^{\text {th }}$ percentile (Table 3 ).

Table 3 Except for ages II-12 months, at least $90 \%$ of the patients were found to be below the $75^{\text {th }}$ percentile in all the others ages

\begin{tabular}{lllllll}
\hline Age in months/percentile & $\mathbf{5}$ & $\mathbf{1 0}$ & $\mathbf{2 5}$ & $\mathbf{5 0}$ & $\mathbf{7 5}$ & $\mathbf{9 0}$ \\
\hline 0-I & $5.40 \%$ & $10.10 \%$ & $24.80 \%$ & $63.60 \%$ & $90.70 \%$ & $96.90 \%$ \\
2-Jan & $6.80 \%$ & $13.70 \%$ & $49.30 \%$ & $82.20 \%$ & $91.80 \%$ & $98.60 \%$ \\
3-Feb & $4.10 \%$ & 20.4 & 59.2 & $91.80 \%$ & $93.90 \%$ & $100 \%$ \\
4-Mar & $3.80 \%$ & $7.70 \%$ & $61.50 \%$ & $100 \%$ & $100 \%$ & $100 \%$ \\
5-Apr & $0 \%$ & $13 \%$ & $56.50 \%$ & $87 \%$ & $100 \%$ & $100 \%$ \\
6-May & $8.80 \%$ & $32.40 \%$ & $58.80 \%$ & $94.10 \%$ & $100 \%$ & $100 \%$ \\
7-Jun & $21.20 \%$ & $27.30 \%$ & $60.60 \%$ & $84.80 \%$ & $97 \%$ & $100 \%$ \\
8-Jul & $0 \%$ & $10 \%$ & $40 \%$ & $80 \%$ & $90 \%$ & $100 \%$ \\
9-Aug & $0 \%$ & $0 \%$ & $14.30 \%$ & 100 & $100 \%$ & $100 \%$ \\
I0-Sep & $0 \%$ & $37.50 \%$ & $37.50 \%$ & $75 \%$ & $100 \%$ & $100 \%$ \\
II-Oct & $10 \%$ & $20 \%$ & $50 \%$ & $80 \%$ & $100 \%$ & $100 \%$ \\
I2-Nov & $0 \%$ & $0 \%$ & $25 \%$ & $62.50 \%$ & $75 \%$ & $100 \%$ \\
\hline
\end{tabular}

Citation: Valencia DV,Vargas EAV, Núñez RB, et al. Motor neurodevelopment of preterm children cohort until one year of corrected age according to alberta infant motor scale. Int Phys Med Rehab J. 2018;3(I):50-54. DOI: I0.15406/ipmrj.2018.03.00074 


\section{Discussion}

Since the objective of the present study is to characterize a retrospective cohort of patients according to their motor development measured by the Alberta Scale, no other statistical comparisons were developed, apart from the descriptive ones with the original study and only our results are compared to give them context within the very logic of the Alberta Scale since a statistical comparison of another type among the samples could lead to erroneous conclusions for many reasons, among them the retrospective nature of our study, the objectives of the study, the differences among the population with which the original study was realized and ours due to the choice criteria, the complexity of the original study in Alberta and the heterogeneity in the age distribution of our sample.

The Alberta Scale was developed as a screening tool of early normal motor development. The patients studied here did not present serious pathologies or diagnosed motor development alterations and they only had the risk factors associated with prematurity which were described (Table 1) by patients who should present normal development curves, considering their background of prematurity. According to the evaluation by the Alberta Scale more than half of our patients had a normal development, and $80.2 \%$ of the patients were placed between normal development and suspicion of abnormal development, the patients with abnormal development were approximately one fifth, so in our study the scale was shown as a useful screening tool of child with normal development, detecting the majority as such.

Having concluded the above, it is important to clarify that in our sample the vast majority of patients were placed below the $75^{\text {th }}$ percentile and a large number below the $50^{\text {th; } ;} 25^{\text {th }}$ and $10^{\text {th }}$, with differences of at least $10 \%$ between the Canadian and our sample (and much superior in many cases as it was described in the results) which could indicate a supra valuation of the deficiencies in the motor development in our preterm population when applied the Alberta Scale, being this result compatible with the international literature of the subject both at the premature level as in the level of local populations of patients evaluated by the scale.

In the Van Haastert study, realized in Netherland, it was found that children with prematurity background had significantly lower scores at all ages when evaluated by the Alberta Scale, even correcting the chronological age, so, according to its conclusions, the reference curves for the Alberta Scale in a population with prematurity background should be adjusted specifically for this population, conclusions reinforced by the fact that the study was carried out in a high income country with a population potentially similar in a socioeconomic level to the original sample and with a sample of 800 patients collected for 12 years. ${ }^{17}$ A systematic review developed by Fuentefria in Brazil that evaluated 101 articles that described and/or analyzed the motor development of preterm infants according to the Alberta Scale, selected 23 articles that fulfilled the selection criteria for the final review, the articles came from USA, Brazil, Taiwan, South Africa, Netherlands and Australia and the authors of the review found that in most of the studies there were found significant differences between the motor development measured by the Alberta Scale in preterm children and term children. ${ }^{15}$

The new reference curves for the Alberta Scale evaluation in Brazil were performed by Saccani R. ${ }^{10}$ updating the work done in 2012 and showed again that the Brazilian population (of preterm and full-term children) presents lower scores in almost all the ages, when being evaluated with the scale and at all ages if children are considered until the corrected age of one year, ${ }^{10}$ similar results were obtained by Cabrera $\mathrm{R}$ et al. in the Maule region, Chile, when generating reference curves for the Alberta Scale, ${ }^{18}$ being studies of south American countries with population potentially more similar to that of our country than the Canadian one.

As a main limitation of our study we have its retrospective nature, from which it raises the fact of not having a chosen sample according to the demographic criteria, the heterogeneity in the age distribution of our sample and the poor fulfillment of the clinical histories that impeded the analysis of associated socioeconomic factors, it is also remarkable the low adherence of the patients to the follow-up programs, which means that the vast majority had only one evaluation record by the tools and it was not possible to follow their evolution over time, so the analyses are only about the first assessment consults of all the patients. Understand with evidence the qualities of the tools that are used in the daily clinical practice is essential to avoid misinterpretations when evaluating the results they give, especially if those are tools that were developed with potentially very different population to the ones that are evaluated in a specific practice. ${ }^{19}$ Misdiagnosis of motor development alterations can derive to the application of unnecessary interventions or otherwise insufficient clinical measures that could affect the patient's quality of life at a very early age.

The Alberta Scale is widely used at a global level to evaluate de motor development of both full-term and preterm children and it can be a truly useful tool, at a great scale, for this purpose in our country. Our study shows that as a screening tool of the early motor development the Alberta Scale is useful, as well as being a tool of easy and relatively rapid application, and that studies should be made to validate and generate reference curves for the country, so that the results of the evaluation by the tool would be even more solid, because currently in the evaluation of patients with prematurity background in our environment there could be a supra valuation, the deviations of motor development, in fact, if we consider the evidence on the subject, this same could be extended to the whole population evaluated by the tool in our country.

\section{Acknowledgements}

None.

\section{Conflict of interest}

The authors manifest that during the execution of the work and writing of the academic document, there were no interests or values any different from the ones stated in the objectives of the investigation, the study was financed in its totality by the author's own resources.

\section{References}

1. Linsell L, Malouf R, Morris J, et al. Prognostic factors for cerebral palsy and motor impairment in children born very preterm or very low birthweight: a systematic review. Dev Med Child Neurol. 2016;58(6):554-569.

2. Soleimani F, Zaheri F, Abdi F. Long-term neurodevelopmental outcomes after preterm birth. Iran Red Crescent Med J. 2014;16(6):e17965.

3. Charkaluk M, Truffert P, Fily A, et al. Neurodevelopment of children born very preterm and free of severe disabilities: The nord-pas de calais epipage cohort study. Acta Paediatr. 2014;99(5):684-389. 
4. Piper MC, Lynn E, Darrah J, et al. Construction and validation of the alberta infant motor scale (AIMS). Can J Public Health. 1992;83(suppl 2):S46-50.

5. Piper MC, Darrah J. Motor Assessment of Developing Infant. 1st ed. Sauders, Philadelphia, USA; 1994.

6. Darrah J, Bartlett D, Maguirre T, et al. Have infant gross motor abilities changed in 20 years? A re-evaluation of the alberta infant motor scale normative values. Dev Med Child Neurol. 2014;56(9):877-881.

7. Syrengelas D. Kalampoki V. Kleisiouni P. et al. Gross motor development in full-term greek infants assessed by the alberta infant motor scale: Reference values and socioeconomic impact. Early Hum Dev. 2014;90(7):353-357.

8. Uesugi M, Tokushiha K, Shimada T. The reliability and validity of the alberta infant motor scale in japan. Journal of Physical Theraphy. 2008;20:169-175.

9. Saccani R, Valentini NC. Brazilian validation of the alberta infant motor scale. Phys Ther. 2012;92(3):440-447.

10. Saccani R, Valentini NC, Pereira K. New brazilian developmental curves and reference values for the alberta infant motor scale. Infant Behavior And Development. 2016;45:38-46.

11. Saccani R, Valentini NC. Cross-cultural analysis of the motor development of Brazilian, Greek and Canadian infants assessed with the alberta infant motor scale. Rev Paul Pediatr. 2013;31(3):350-358.

12. Morales E. Alberta infant motor scale: Analisis de la validez y fiabilidad de la version española y su aplicacion en la determinacion de trayectorias del desarrollo motor grueso en niños nacidos pretermino. Tesis doctoral. Universidad Internacional de Cataluña, Spain; 2016.
13. Serrano M, Camargo LD. Reproducibilidad de la escala motriz del infante de alberta (alberta infant motor scale) aplicada por fisioterapeutas en formación. Fisioterapia. 2013;35(3):112-118.

14. Fuentefria RN, Silveira RC, Procianoy RS. Motor development of preterm infants assessed by the alberta infant motor scale: systematic review article. Jornal de Pediatria. 2017;93(4):328-342.

15. Borrero R, Hernández M, Toro AM. et al. A propósito de una nueva clasificación del embarazo a término resultados neonatales en una clínica de tercer Nivel de atención en Cali, Colombia. Un estudio de corte transversal 2013. Revista Colombiana de Obstetricia y Ginecología. 2013;67(4):271-277.

16. Caserio CS, Pallas CR. Seguimiento del prematuro/gran prematuro en Atención Primaria. Rev Pediatr Aten Primaria. 2009;11(17):443-450.

17. Van Haaster IC, De Vries LS, Helders PJ, et al. Early gross motor development of preterm infants according the alberta infant motor scale. The Journal of pediatrics. 2006;149(5):617-622.

18. Fernandeza RC, Inostrozaa JE, Gajardoa KG, et al. Valores referenciales del desarrollo motor grueso de infantes sanos de 5 a 18 meses de edad pertenecientes a la región del maule obtenidos a través de la escala motora infantil de Alberta. Revista de estudiosos en movimiento. 2104;1(1):45-53.

19. Spittle A. Doyle L. Boyd R. A systematic review of the clinimetric properties of neuromotor assessments for preterm infants during the first year of life. Dev Med Child Neurol. 2008;50(4):254-266. 